\title{
Ideas of the cosmism philosophy natural- scientific direction within media space and social-economic space
}

\author{
Liudmyla Orochovska ${ }^{1, *}$, and Uliana $\operatorname{Koshetar}^{1}$ \\ ${ }^{1}$ National Aviation University, 03058, 1 Kosmonavta Komarova, Kyiv, Ukrain
}

\begin{abstract}
The article examines the influence of cosmism ideology and its orientation at principles of total interconnection, unity, obligatory coordination of human activity with the principle of world integrity on the formation of media space and socio-economic space of the information society. It displays that inwardness within the formation of humanity unity has been emphasised by the cosmism representatives Vladimir Solovyov, Nikolai Fedorov, Nikolai Berdyaev, Konstantin Tsiolkovsky, Vladimir Vernadsky, Edouard Le Roy, Pierre Teilhard de Chardin who manifested the world view position considering human, their past, present, and future through the lens of correlation with space. The research distinguishes the crucial role of cosmism ideology in development of modern media culture. It highlights the fact that, within the information society where formation of network communication systems provides the opportunity to shape global interaction systems enabling integrity of world culture or any national culture, priorities of cooperation and mutual aid ought to become dominant for mass media activity regardless of the civilisations, nations, regions, communities they represent. Policy in the sphere of media culture must be directed at the operation of communication network in the interchange mode, prevention of the situation when demassification of mass media may lead to localising, closing cultures of certain ethnic or religious groups.
\end{abstract}

\section{Introduction}

During different historic stages, media space growth has played a constructing role in social existence - primarily through the growth of social space. These stages were: invention of writing and usage of papyrus - the factors that strengthened bureaucratic and centralised organisation of distant regions and influenced the process of creating empires in the Ancient world; invention of book-printing that intensively consolidated media space within country borders, extended opportunities of providing education to the public. However, only the emergence of electrocommunication (telegraph, telephone, radio) in $19 \mathrm{c}$. allowed the establishment of economic, political, cultural relations on the global level actualising the philosophical development of ideas regarding creation of the single planet-scale country, the world pattern of the Earth. It was this period when the ideology of cosmism

\footnotetext{
* Corresponding author: ola-2011@ukr.net
} 
found its formation; these ideas include comprehending relations of human with space, planet, society, posing a problem of human responsibility for the results of their activity.

Development of modern mass media, predominantly the Internet and cellular communication, provides facilities for expansion of network individualism as a dominant form of sociability. The Internet enables individuals to build their networks on-line and offline based on their own interests, values, projects. New virtual communities, socialisation forms, lifestyles, and forms of social organisation appear. Therefore, within the modern crisis of the Western society, the switch of media culture to cosmism ideas advocating the ideology of human-world harmony acquires particular topicality as an important source of society world view formation.

In this article, the author relies on the concepts of cosmist philosophers Nikolai Berdyaev, Vladimir Vernadsky, Vladimir Solovyov, Nikolai Fedorov, Pierre Teilhard de Chardin, Konstantin Tsiolkovsky considering the space-scale future of humanity. In the study about the noosphere, the cosmism ideologists Pierre Teilhard de Chardin, Vladimir Vernadsky emphasised the dependence of the fate of humanity and all living organisms on the fate of the Universe. Today, under the conditions of aggravating global problems, cosmism is the world view crucial for their solution. Therefore, it is important for modern media culture to be based on the paradigm of civilisation development the ideas of which are introduced by cosmist philosophers.

\section{Materials and methods}

Various methods were used during the research. The system-structured approach gave the possibility to investigate each element of the philosophical discussion focusing on the entire. The hermeneutic method was used for understanding and explanation of philosophical texts of M. Berdyaev, V. Vernadsky, V. Solovyov, M. Fedorov, P. Teilhard de Chardin, K. Tsiolkovsky, and others. The symbolic-existential method was used to interpret symbols. The cognitive approach gave a glance at philosophical discussion through the prism of the way of thinking, perception, and understanding. Methods of comparative conceptual analysis and retrospective modeling were important during this investigation, and allow to analyze conceptual invariants, and to compare world outlook models of texts, and the subjects of discussion.

\section{Results}

In 1844 Samuel Morse opened a telegraph line connecting Washington and Baltimore which allowed to establish immediate information transfer regardless of the significant distance between these cities. Creation of the single media space between Europe and America was enabled by laying a telegraph cable through the Atlantic Ocean (1858) and installing radio connection between these parts of the world by Marconi (1901). Extension of media space to the global level has become a factor actualising philosophical development of ideas regarding creation of the single planet-scale country, the world pattern of the Earth, regarding expansion of culture covering the whole the planet.

Cosmism representatives emphasised inwardness within the formation of humanity unity, i.e. the world view position which considers human, their past, present, and future through the lens of correlation with space. Vladimir Solovyov believed in future union of humanity, and first of all in God-humanity: 'We are to view humanity in its integrity, as a big creature including everybody or as a social organism living organs of which constitute different nations. From this perspective, it is obvious that no people can live in itself, through itself and for itself, but the life of every people is only a particular fraction 
in the mutual life of humanity'. The God-humanity process was recognised by Vladimir Solovyov as evolution of the natural and social world.

The society dominated by 'good without evil' was a dream of Nikolai Fedorov. According to him, it can only be the society where death will be defeated with the help of science, and all deceased generations will be brought back to life. This way higher justice will be reached, and, consequently, so will the higher good. Thus, Nikolai Fedorov manifested the idea of humanity union in aggregation of all of its past and future generations.

In his paper 'New Middle Ages', Nikolai Berdyaev stated that the single human society is to be established primarily according to the spirit principle as a spiritual community of existential subjects united by mutual history. Within this society, which will become 'the collective body of freedom', the material turns into the spiritual. Humanity for him isn't an aggregation of faceless individuals, rather a unity of independent personalities each of which is responsible for itself, for the others, and eventually - for the fate of the world as well.

The World War I and the revolution in 1917 were recognised by Nikolai Berdyaev as the events which aggravated the issue of the global world pattern to the uttermost and led to necessity of the expansion of culture on the whole Earth surface. He wrote: 'The current world war, which is continuously growing and threatening to consume all countries and peoples, seems to be deeply opposite to this old dream about the world unity, the single global state. Such a terrible war might look like one destroying the unity of humanity. However, it's only on the face of it. From the deeper point of view, the world war aggravates ne plus ultra the issue of the global world order, of the expansion of culture on the whole Earth surface. The current historical time is similar to the Migration Period. One may feel that humanity enters a new historical and even cosmic period, a certain great enigma being predicted by no scientific forecasts and negating all doctrines and studies' [1].

In his works, Konstantin Tsiolkovsky described single humanity able to settle in distant worlds. For the sake of future mutual understanding between peoples, he even invented a universal alphabet. The scientist believed that not only Earthmen would unite in future: 'Not only each planet undergoes unification, but the whole aggregation of them... After unification of each planet, unification of each solar system is inevitable'.

Vladimir Vernadsky, Edouard Le Roy and Pierre Teilhard de Chardin also discussed the unity of not only Earthmen, but also the cosmic unity of all thinking creatures in the noosphere. If Pierre Teilhard de Chardin and Edouard Le Roy saw it as a sphere of divine mind, Vladimir Vernadsky interpreted it from the positions of materialism. In their papers, Pierre Teilhard de Chardin and Vladimir Vernadsky studied the process of humanity unification at the levels of kindreds, tribes, and then peoples, countries. According to them, human thought develops with increasingly greater power and speed, and already in the 20 c. due to the means of communication humanity becomes integral and the noosphere covers the whole Earth. In the paper 'The Phenomenon of Man' Pierre Teilhard de Chardin noted: 'The exit for the world, the doors for the future, the entrance into superhumanity open forward and not for several privileged individuals, not for the one chosen people! They will open only under the pressure of all together and in the direction in which all together can unite and fulfil themselves in the spiritual renewal of the Earth'. He saw the aim and task of humanity in reaching the Omega Point where the complete phenomenon of human will unfold. For him humanity as a single creature meant fulfilment of the desire for spiritual commonality embedded in human, aggregation of the organism as a whole in its unity. Nevertheless, it was a project intended for the natural process of unification as aggregation of the Spirit and didn't suppose any forceful actions for its realisation. It must 
have been a process of cultural synthesis, meeting of cultures, their interweaving on the basis of mutual problems and tasks of humanity, commonality of its fate.

Main provisions of Vladimir Vernadsky's study about the noosphere were published in 1944 in the paper 'Some Words about the Noosphere'. The scientist noted: 'In the 20th c., for the first time in the Earth history human cognized and covered the whole biosphere, finished the geographic map of the planet, settled over all of its surface. In regard of its life, humanity became a single entity. There is no such spot on the Earth where human wouldn't be able to live if they needed to... And at the same time, due to powerful technologies and achievements of scientific thought, due to radio and television human can communicate immediately with anybody from any part of our planet' [2].

Later, in his work 'Scientific Thought as a Planetary Phenomenon', Vladimir Vernadsky raised the issue of global unity of humanity on the reasonable, extremely humanised ecologised basis - i.e. formation of the sphere of mind (noosphere) as a qualitatively new state of human civilisation. 'Historic process is changing before our eyes. For the first time in the history of humanity interests of the masses - each and every one and the free thought of a personality define the life of humanity, measure its beliefs about justice. Humanity as a whole is becoming a powerful geological force. And humanity, its thought and labour, face the issue of transforming biosphere out of concern for the freely thinking humanity as a single entity. This new state of biosphere which we are approaching without noticing is the 'noosphere' - he wrote.

The main force creating noosphere, according to Vladimir Vernadsky, is the growth of scientific knowledge. In the centre of the system of noosphere world view, which must provide socially efficient exploration of the world, there already is not just a human with an abstract humanistic system of values, even not a national-territorial state, but humanity with a specific system of material and spiritual needs and survival interests of today and future generations. 'Humans have for the first time realised that they are inhabitants of the planet and can - must - think and act in a new aspect, not only in the aspect of a separate personality, family or kindred, states or their unions, but also in the planetary aspect'

Thus, there are sufficient grounds to consider Vladimir Vernadsky to be the scientist who closely approached formation of the belief that the world is the Universe. Although, characterising human and humanity, the scientist uses the notion of 'living substance', he didn't equal it to live weight but emphasized its social specificity. Not a separate human, but humanity as a whole becomes the factor which shapes the noosphere. And solely on the basis of scientific knowledge the background for uniting all people in the universal entity - humanity - is created. Vladimir Vernadsky stated that it is science that must become that force uniting humanity. Since it is scientific thought that creates the noosphere. It is science that is single and same for 'all times, social environments and national unions. However, this conception humanity approaches through hard historical experience because during millenniums both religion and state institutions have been trying to create a unity and force everybody into the single conception of the sense and goal of life. During its history of thousands of years, humanity has never had such a single conception'. And science is also that information about the world which is transferred, accumulated via media space as a subspace of socio-economic space expanded to the level of the Universe.

In the late 20th c., cultural exchange, cultural integration find drastic strengthening due to the emergence of satellite television, information-computer networks operating on the basis of the digital method of information transmission. At this time, information space united national, regional, and local electronic networks and ultimately passed beyond the territory borders. According to Oleh Bazaluk, 'if the borders of living matter are limited by the efficiency of genetic programmes and types of their inheritance, the borders of intelligent matter are technically infinite' [1]. In the modern world, economic, financial, 
and commercial relations have penetrated the whole planet leaving separate nations and countries no alternative to their joining the single world economy. Within these realia, it is important for the scientific community of the country to be directed at taking part in the world economic connections of the global network society through bringing there a specific intellectual product.

Discovering reasons for expanding cultural borders, Niklas Luhmann notes that functional relations within society constantly require intercrossing of territorial borders, i.e. receiving news from abroad, petitioning about international credits, military and political security measures resulting from the events abroad, copying school and university systems of leading countries etc. This weakening of space obstacles is deepened by the fact that global communication requires almost no time expenditures and can be fulfilled with the help of telecommunication. Information doesn't have to be transported like things or people anymore. Thus it is electronic communication that provides expansion of media space to the planet-scale conforming to the interests of politicians, businessmen, figures of science and culture.

In the age of informatisation, such words like 'media space', 'radio space', 'television space', 'cyberspace', 'information space' etc. have become commonly used. In the process of wide computer technology introduction, the 'information space' phrase has become quite popular among scientists, mass media representatives, politicians. Generally, this phrase is used to define media-, radio-, tele-, and cyberspace. The key element of all these space kinds is information in its different forms and manifestations. Within society computerisation, information space expands increasingly, and this fact is noted by almost all researchers examining specific features of the modern historic stage of humanity genesis. Modern media space combines certain kinds: global, national, regional etc. This space is free and chaotic providing an individual with a wide area of opportunities for selfdetermination. Electronic mass media allow to shape one's own media environment (global or local) encompassing spheres of certain interests (economy, social institutions, social consciousness, spiritual and material culture).

Media space is also transformed under the influence of technologies, and in information society it is affected by information-communication technologies. Within this context to claim that technology changes directed at information functioning in society produce significant influence on the quantitative parameters of the space information turnover takes place in. It is constantly expanding because of: 1) expansion of communication sphere through the use of information-communication technologies; 2) acquisition of the increasing amount of information; 3) acceleration of the process of receiving the latest knowledge, even in the on-line mode. There is being observed a drastic increase in the number of social networks based on the technologies accessible for the most distant locations on the planet. Thus, media space under the conditions of informatisation penetrates the whole socio-economic space, all social practices where informationcommunication technologies are principal.

As far as is known, the category of 'space' has been used in philosophy for establishing characteristics of the world in general and for describing separate subjects in natural sciences and in everyday speech since Antiquity. After the emergence of new information mass media, the word 'space' found its popular figurative use as defining not only a geometric and not even a geographic image of the world, but it is rather being used as a metaphor suitable for describing virtual reality.

Commutation and transport technology improvement creates a speed-up effect in the sphere of everyday experience of space perception. The new perception of space and time would be observed by people using the first railways; subjectively it seemed to them that the distance was shortening. The new understanding of space and time was influenced by air transportation and the up-to-date methods of information transferring, storing, and 
processing caused by the emergence of computer and the Internet. After the invention of radio, television, the Internet, the role of immediate information is increasing, and social life is speeding up due to the 'compression' of time and space. In 1991 the world information network was created, and the world became informationally locked. Douglas Rushkoff calls this new reality an 'infosphere'.

Synonymic to the notion of 'infosphere' is the notion of 'cyberspace', as it is highlighted by Maya Volodina: 'Information society' gave way to a special spacio-temporal phenomenon which is the novel information infrastructure called 'cyberspace' or 'noosphere' [3] causing transformation processes in all social spheres.

The emergence of a single information space was enabled by technological provision of multidimensional and multifaceted information, forms, and methods of its producing, codifying, saving, storing, processing, and transferring. The world computer network undertakes services of post, telegraph, telephone, copying machines. The Internet and mobile communication have changed our life style. Technology development enabled wireless connection in any time and place. This is symbolised by Nokia banner saying 'Connecting people'. Cellular communication complements the Internet becoming a vital component of media space and having dramatically freed communications from site specificity. Earlier coordination of the meeting participants would end the moment they leave the house with a telephone, but the emergence of mobile telephones has overcome this obstacle. "Mobile "phonespace" allows the existence of continuous and immediate meeting cultures where place, time, participants and topic are defined with the help of a phone call or a text,' says John Urry. Mobile telephones eliminated the need in clear forehand coordination since people can keep in touch constantly regardless of their location.

The type of future decentralised society described by Marshall McLuhan as a 'global village' is based on application of electronics and mass media. This society is characterised by: on one hand, decentralisation and diffusion; on the other hand, consistence of communications and solidarity. This village is open to cosmopolitan influence of planetary communications; it is private, intimate, solidary. Due to telecommunications, a new type of solidary connections appears which, according to Marshall McLuhan's sensible remark, is immediately and continuously drawing us into all other people's problems. It has brought dialogue onto the global scale. Its message is Total Change, ending psychic, social, economic, and political isolation. Old civilian, social, and national organisations are not valid. Nothing can be more distant from the new technology spirit than 'a place for everything and everything in its place.' You can't hide at home anymore. The mentioned changes are happening because of mass media expanding communication and transforming space-time continuum: compressing space, enabling time recurrency, creating conditions for information accessibility in different countries in both present and past.

\section{Discussion}

Electronic media created a new type of communication based on the available free access to the global information space. Regarding cultural globalisation, Feokhary Kessidi justly says: 'Diversity unity and unity diversity constitute the dialectics of life and existence. Therefore, the idea of creating a single culture, superethnos or "megasociety" in the nearest future, regardless of the global processes occurring today, is an illusion, a dystopia putting a disguise of the dream on reality' [4]. The same position is held by Alvin Toffler who, sharing his forecasts, predicts that the new society will encourage 'versatile patchwork rapidly changing life styles'.

The global doesn't deny the local; therefore, the phenomena, occurring under the influence of globalisation in media space, can be defined by the term 'glocalisation' 
introduced by Gordon Robertson and combining globalisation and localisation in culture. Though globalisation does stipulate interaction and mutual enrichment of ethnic cultures, it doesn't eliminate and can't eliminate diversity of cultures. Media space also becomes glocal, i.e., global and specifically addressed at the same time.

Globalisation of information space erases the borders created by several governments which limit freedom of speech and right to objective information with various prohibitions. Existence of independent news TV channels, e.g., Al-Jaheera, allows the world audience to receive alternative perspective on the events happening as it was during the war in Iran. Members of different societies can share ideas using for getting information not only local mass media, but analysing information of the wide range of mass media from other countries oriented at the world audience. It undermines the dominant position of the social norms established by the elite of a certain society with the purpose of producing influence on the masses. Information accessibility frees human from receiving only one complex of ideas and norms, enables access to alternative points of view.

However, even democratic governments enforce certain limits on access to certain Internet websites displaying information which is not desirable for official bodies. Indeed, the USA bans the WikiLeaks website. There is no decisive position opposing limitation of access to websites. On one hand, access to websites threatening moral and physical health of citizens must be limited; on the other hand, according to John Barlow's remark, these measures can 'prevent spreading of the virus of free thinking by building fortifications on the borders of Cyberspace. These measures can restrain an epidemic for some time, but they won't be working in the world which will be soon conquered by the bit-bearing communication means'.

Invention of the Internet resulted in the emergence of a single global market where millions of new consumers and manufacturers became able to buy and sell goods and services. Expanding media space is increasingly affecting social consciousness as a powerful means of information, cultural and educational contacts, as a factor of development of personality creative talents and is changing the whole sociocultural situation. A significant number of people received an opportunity to jointly work on various projects living in different parts of the planet.

Access to the world information space requires a command of international languages since otherwise it is impossible to get acquainted with cultural heritage of other peoples. On the other hand, it may lead to destruction of cultural and lingual diversity and speed up disappearance of languages, customs, and traditions. Therefore, one of the principal tasks of information age is the necessity of finding a balance between protecting ethnic and economic rights of authors and preserving social access to literary works, scientific and fiction papers, and to services in the field of culture.

Modern media space is rather heterogeneous since access to mass media depends on many terms: political, sociocultural, economic. The term 'digital inequality' has become commonly used; it denotes inequality among people, groups, nations on account of Internet connection. Expensive Internet connection, so called 'digital inequality' limit access to cyberspace creating 'North - South' vectors at both global and national scale.

The past decades of global development showed that the process of globalisation has two sides: an objective side, a regular stage in the world development, a historic process of shaping the world unity in the spheres of economy, finance, information, politics, culture; a subjective side reflecting the Western countries longing for controlling this process. The gap between the group of the most developed countries having reached the level of information society and the rest of humanity is becoming bigger, particularly on account of living standards. For most people the advantages of globalisation are unavailable. As the author stated in one of her papers, 'the face of globalisation is rather contrast: highly developed countries enjoy all of its benefits whereas others have to enter fierce competition 
to come close to these countries, and some even must admit themselves to be resource colonies of industrially developed countries' [5]. Within global economy, information technologies become one of the crucial elements of foreign policy, and creation of a new economy based on technological progress depends on political processes happening in the country. Corporations may locate production in different places depending on costs, commercial risks, political and social-economic conditions. Communication technologies enable managing financial flows and transferring money to other regions and countries with the help of a keyboard; this way one may start an artificial financial crisis leading to a political one.

Competitive abilities of each country in the world economic contest is defined by its willingness to respond to modern challenges. The first positions are taken by countries that have reached the most significant achievements in creation of modern intellectual potential and in indices of its fulfilment. The rise of the concept of the European Education Space or the European Higher Education Area (late 1970's - early 1980's) resulted from desire of the Western Europe integration ideologists to accept modern challenges and to create more efficient mechanisms of education and science state support. Integration actions objectively lead them to formulating principles of creating the European Education Space and to their confirmation in the Bologna Declaration (19 June 1999).

The European Higher Education Area has the major objective to close the gap in economic competition with the USA which is becoming bigger. It is presupposed that the Bologna process will provide real mobility of citizens from different countries within the education space and on the European labour market, recognition of diplomas and qualifications, attraction of European education for foreigners. These dividends are achievable only for countries with high level of intellectual potential and high social living standards.

Economically developed countries accumulate the latest world inventions and implement them, divert big sums of money as grants for young scientists. Financing scientific projects is becoming a powerful factor in development of these countries. Thus, international rivalry is unfolding today in the sphere of science and education, and competitive abilities depend on intellectual potential of countries, on well-trained and highly-educated professionals. Now, it's not material sphere that defines development level of a country, but level and quality of applying information technologies.

\section{Conclusions}

Modern globalisation processes have a lot of contradictions and are accompanied by the processes of fragmentation, localisation, cultural conflicts, national problems. Communication among people, exchange of values and ideas have reached a new scale and caused anxiety of the many concerning globalisation which may lead to the loss of values and life style, threaten local and national identity. Correspondingly, it gave rise to xenophobia and conservatism. Spiritual crisis in society leads to degradation of personality, escalation of its apathy and estrangement, intensified domination of false values in society resulting in antisocial behaviour, aggression, military conflicts, international conflicts, terrorism etc.

Formation of network communication systems allows the opportunity to shape global interaction systems providing integrity of the world culture or any national culture. Priorities of cooperation and mutual aid ought to become dominant for mass media activity regardless of the civilisations, nations, regions, communities they represent Policy in the sphere of media culture must be directed at the operation of communication network in the interchange mode, prevention of the situation when demassification of mass media may lead to localising, closing cultures of certain ethnic or religious groups. Since mass media 
are intermediaries between state and society, power and human, cosmism ideas directed at cosmic prospects of humanity development, recognition of its mission obtain particular topicality when states conduct their policies in the sphere of media culture. It is important that in modern society full of interethnic, intercivilisational conflicts, within the global crisis, there would be a rise of the ideas developed by cosmists: priority of social interests over interests of personality, advocacy of cooperation over competition, the idea of mutual aid not fight.

\section{References}

1. O. Bazaluk, Philosoph. Cosmol. 12, 195-196 (2014)

2. V. Vernadsky, Some Words about Noosphere. Selected Works (2005)

3. M. Volodina, The Language of Mass Media as the Main Leverage on Mass Consciousness. The Language of Mass Media (2008)

4. F. Kessidi, Globalisation and Cultural Identity (2003)

5. L. Orokhovska, Globalisation and Globalism. Bulletin of the National Aviation University. Philosophy. Cultural Studies: proceedings. NAU. 10, 75-80 (2009)

6. N. Berdyaev, The Fate of Russia (2004) 